\title{
Instructional Design vs Learning Design: Trends and Patterns in Scholarly Landscape
}

\author{
Begum Sacak, Northwestern University \\ Aras Bozkurt, Anadolu University Turkey \\ Ellen Wagner, University of Central Florida
}

The word instructional design has been widely used to depict a discipline that is concerned with understanding and improving the process of instruction (Reigeluth, 2013). Instructional design is sometimes interchangeably used to refer to different terms such as learning design. In the current era, Learning Design can be considered as an amalgamation of several contemporary design traditions actively used within current teaching, learning, training, and development professions. It comes from foundations in Instructional Design, and its variants of Instructions System Design, Instructional System Technology, Instructional Technology and Instructional Science. It has borrowed heavily from Experience Design, and has extended that mindfulness about user experience into a focus on Learning Experiences. The different terminologies have been evolving, and they have been influenced by constant developments in learning sciences and our collective approaches to how learning should be designed. However, there is still widespread confusion about what these terms entail (Maloney, 2016; Lieberman, 2018). From an epistemological perspective, it is crucial to understand the implications and true meanings of these various titles to be able to frame future practices and establish credibility.

In this study, 513 research articles and proceedings that include the specific keywords instructional design and learning design in their titles were analyzed using descriptive statistics (to offer a time trend analysis for these publications), text-mining (to analyze lexical relationships in the titles and abstracts of the sampled articles), and social network analysis (to investigate keyword patterns) approaches. The results of the social network analysis and text-mining demonstrated that in publications that have instructional design in their titles, certain themes emerged such as theory-driven approaches, technology-informed design, instructional design for higher education, and keyword patterns related to assessment and evaluation whereas in publications that have learning design in their titles resulted in themes such as design-thinking and user experience-driven approaches, online learning-informed designs, analytic approaches and engagement-based learning design. The results were discussed in the light of the emerging themes to provide an interpretation of how the use of these keywords have been evolving and offer a glimpse on the future directions in our field with specific emphasis on instructional design, learning design and other learning design-based practices.

\section{References}

Lieberman, M. (2018, September 26). Learning engineers pose challenges and opportunities for improving. Inside Higher Ed. https://www.insidehighered.com/digital-learning/article/2018/09/26/learning-engineerspose-challenges-and-opportunities-improving

Maloney, E. (2016). A Shift Toward Learning Design: What It Isn't, Why It's Needed, and Why It's Right For You? EdSurge. Retrieved January 5, 2020 from https://www.edsurge.com/news/2016-12-05-a-shift-towardlearning-design-what-it-isn-t-why-it-s-needed-and-if-it-s-right-for-you

Reigeluth, C. M. (2013). What is instructional-design theory and how is it changing. In C. M. Reigeluth (Ed.). Instructional-design theories and models: A new paradigm of instructional theory. Lawrence Erlbaum Associate

Saçak, B., Bozkurt, A., \& Wagner, E. (2021). Instructional design vs learning design: Trends and patterns in scholarly landscape. Presented at The Association for Educational Communications and Technology (AECT) 2021 Virtual International Convention. November 2-6 2021, Virtual \& Onsite; Chicago, Illinois, USA.

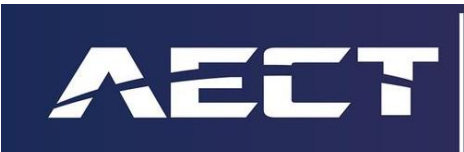




\section{Instructional Design vs. Learning Design: Trends and Patterns in Scholarly Landscape

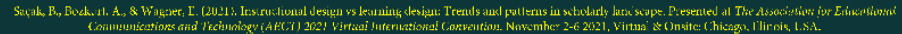
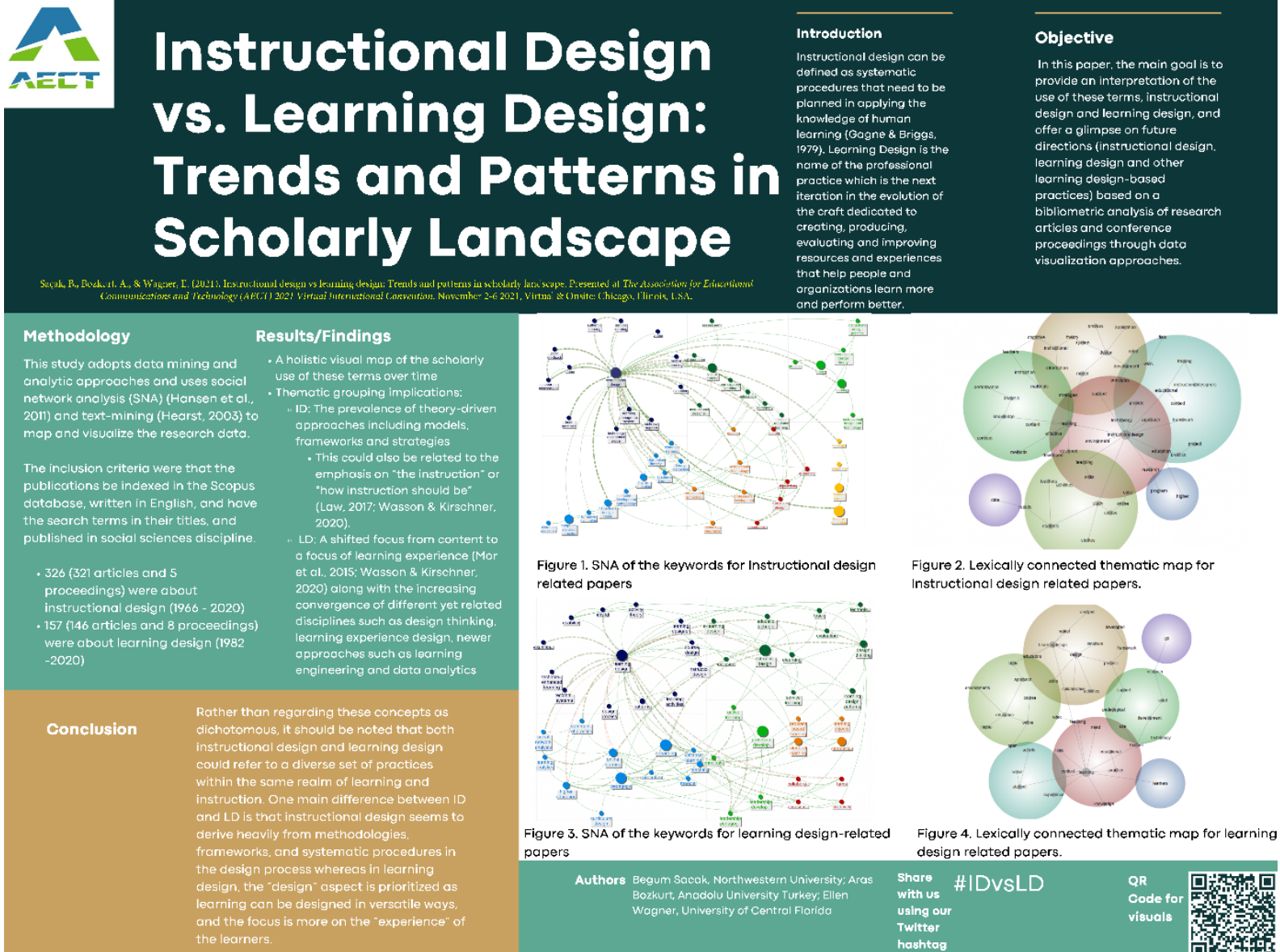

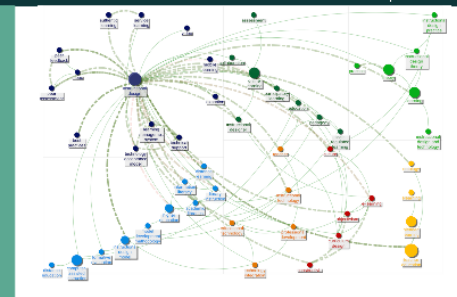

Figure 1. SNA of the keywords for Instructional design related papers

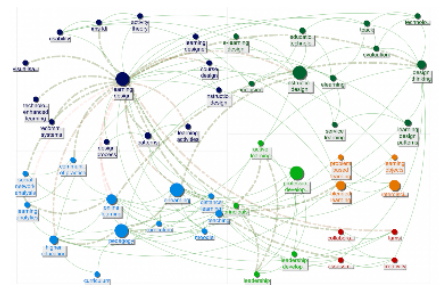
Figure
papers

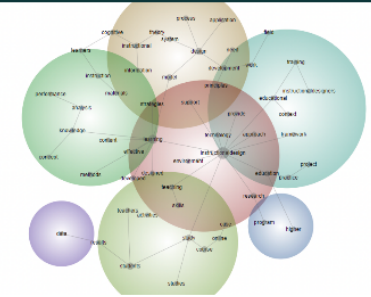

Figure 2. Lexically connected thematic map for instructional design related papers.

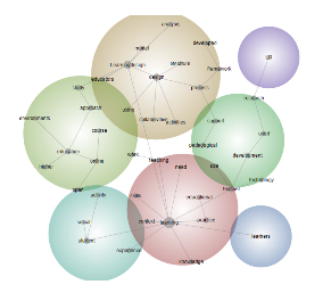

Figure 4, Lexically connected thematic map for learning design related papers.

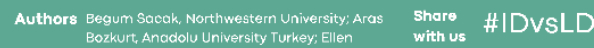




\section{Charts}

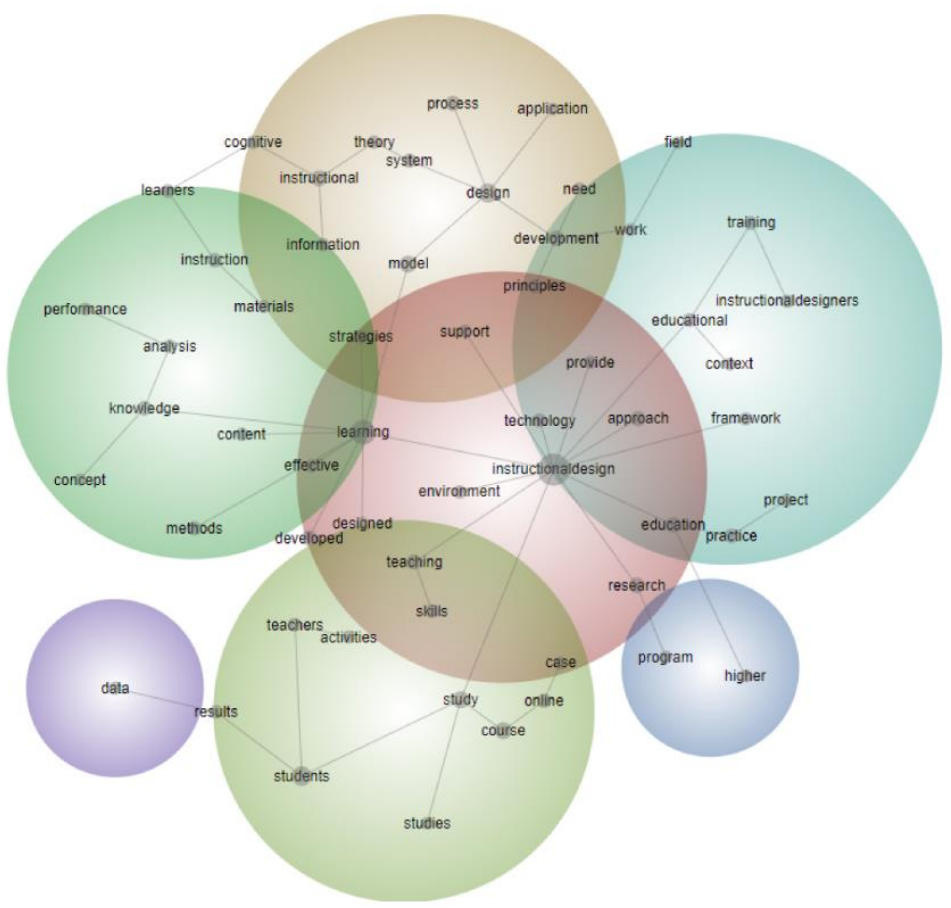

Figure 2. Lexically connected thematic map for Instructional design related papers. 


\section{Charts}

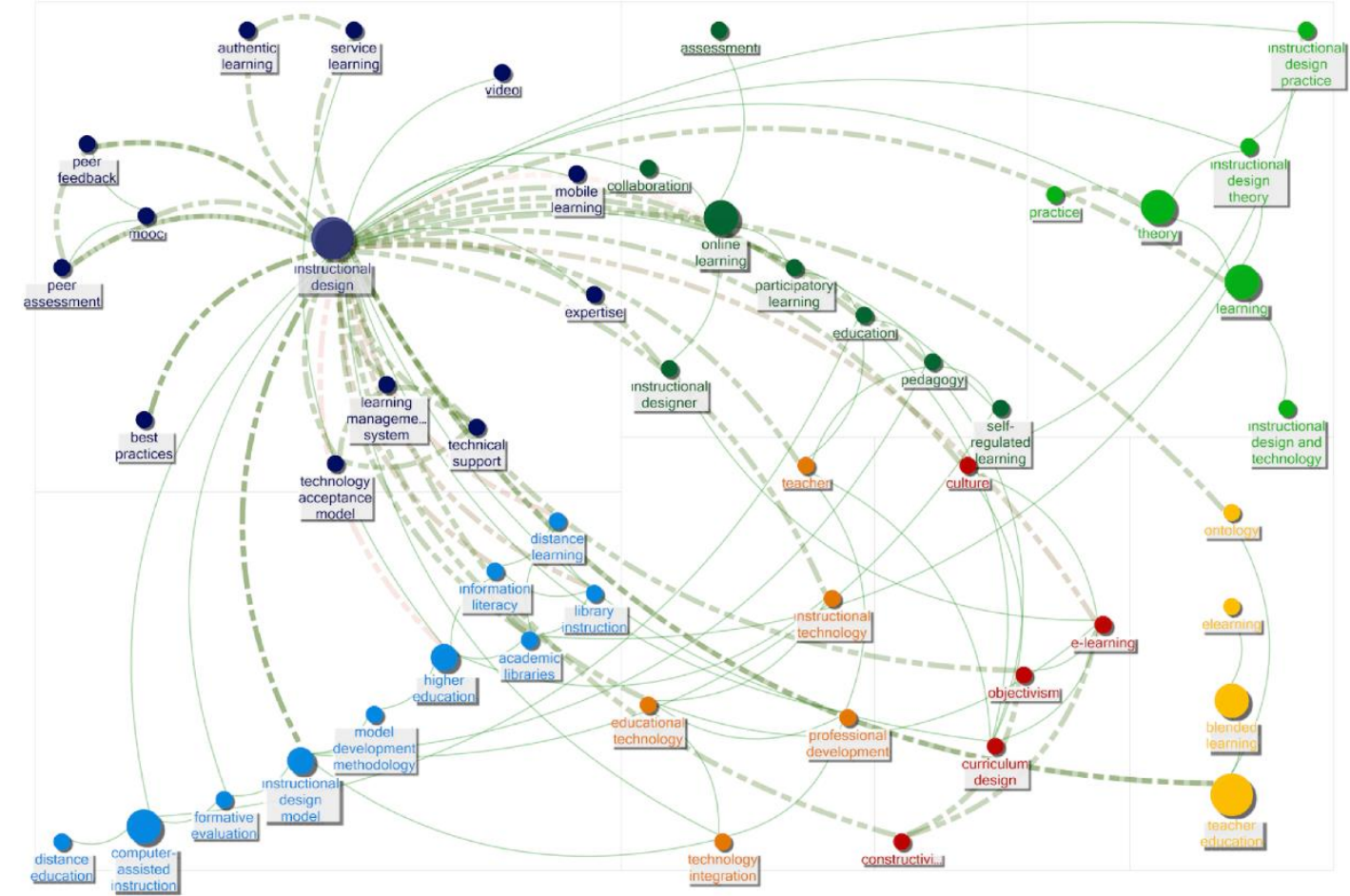

Figure 1. SNA of the keywords for Instructional design related papers 


\section{Charts}

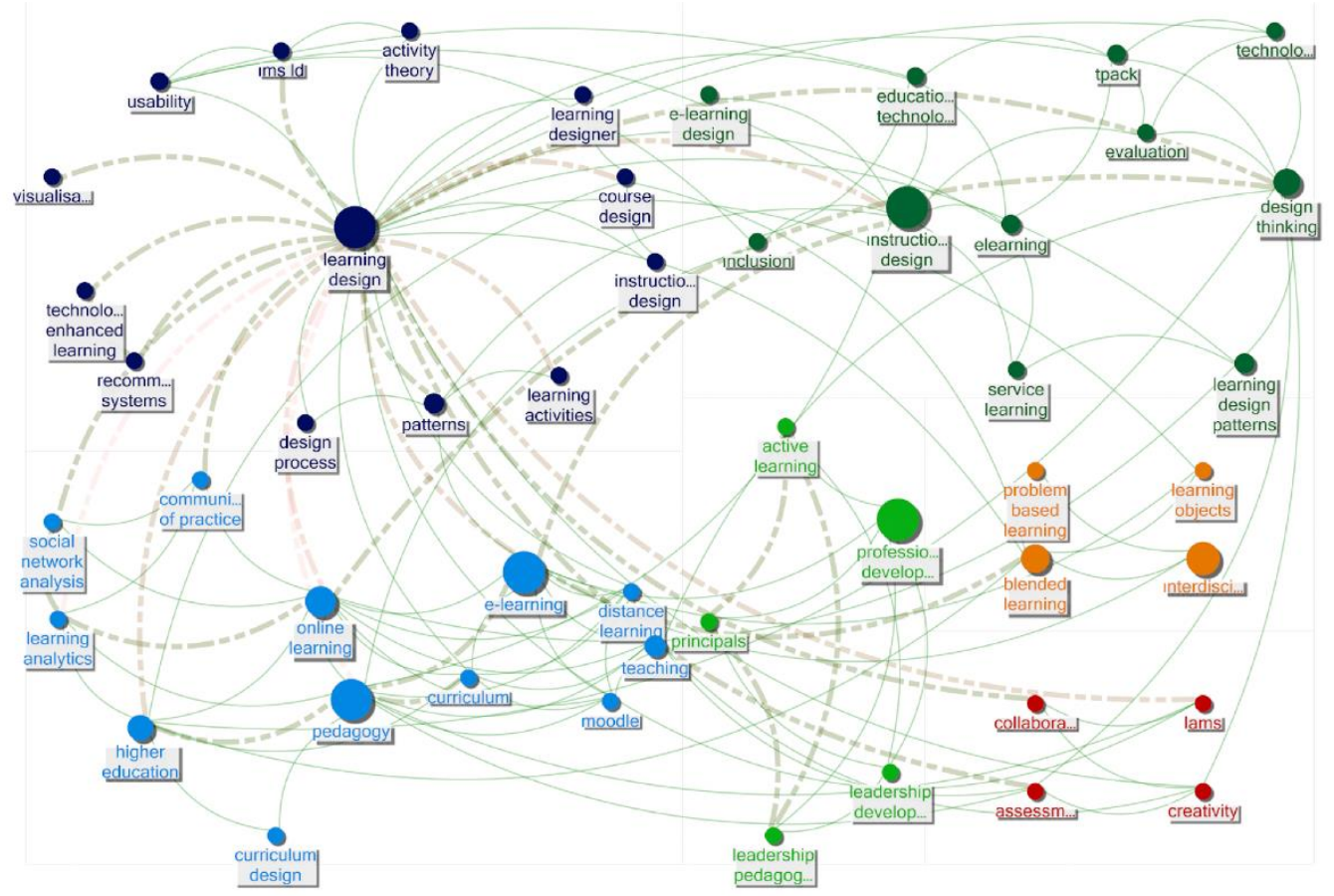

Figure 3. SNA of the keywords for learning design-related papers 


\section{Charts}

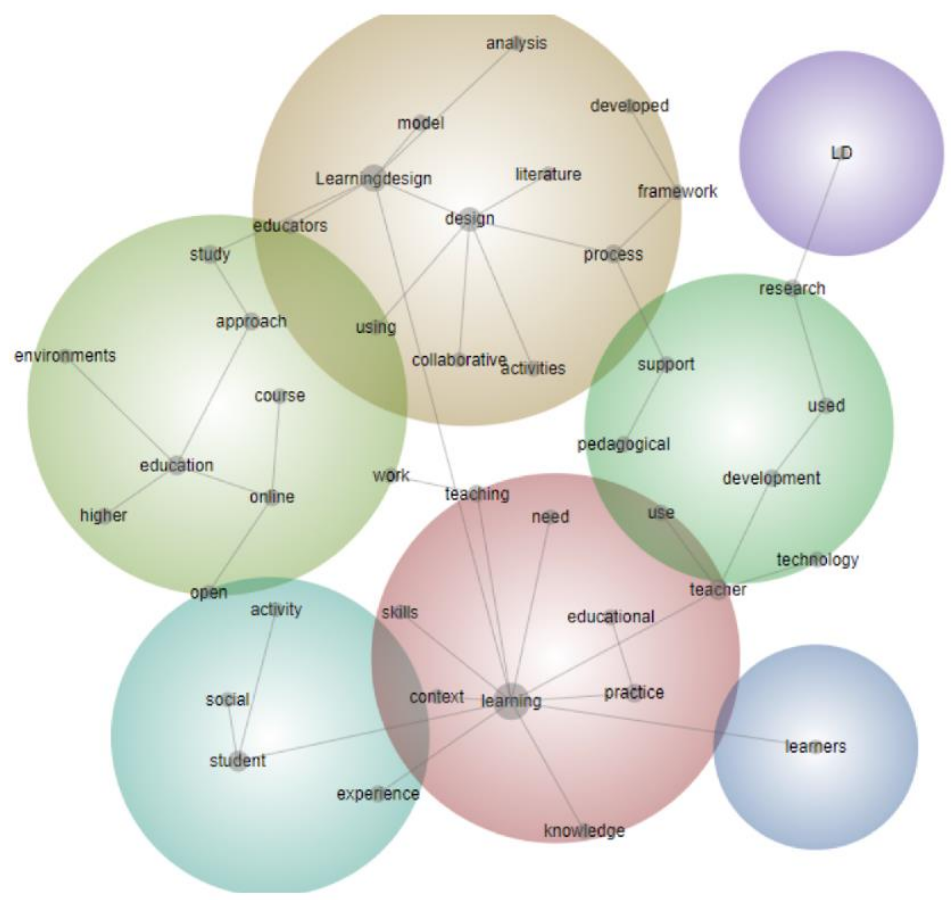

Figure 4. Lexically connected thematic map for learning design related papers.

Saçak, B., Bozkurt, A., \& Wagner, E. (2021). Instructional design vs learning design: Trends and patterns in scholarly landscape. Presented at The Association for Educational Communications and Technology (AECT) 2021 Virtual International Convention. November 2-6 2021, Virtual \& Onsite; Chicago, Illinois, USA. 